
D:\Nsurg\Vol. 23, No. 4, Oct. - Dec., 2019\Nsurg-15.Doc
Fig. 1-2 Color
(A)
P. $257-263$
IV

ORIGINAL ARTICLE

\title{
Outcome of Endoscopic Repair of CSF Rhinorrhea with Endonasal Endoscopic Approach in Terms of Success of Repair
}

\author{
MUHAMMAD ISHFAQ, TALHA ABBAS, MUHAMMAD AKMAL, NABEEL CHOUDHRY, \\ ADEEB-UL-HASSAN, OMAIR AFZAL, IMRAN SIDDIQUI, KHALID MAHMOOD \\ Department of Neurosurgery Unit II, Punjab Institute of Neurosciences, Lahore - Pakistan \\ DOI: https://doi.org/10.36552/pjns.v23i4.378
}

\begin{abstract}
Objective: This descriptive case series conducted to evaluate the outcome of CSF rhinorrhea repair with the Endonasal Endoscopic approach in terms of success of the repair.

Materials and Methods: The study was conducted at Neurosurgery department, Unit II, Punjab institute of neurosciences, Lahore. This study involved 40 patients aged between 3-80 years of both genders diagnosed of CSF rhinorrhea with presented with in 1 week after trauma and spontaneous and postoperative cases.

Results: The age of the patients ranged from 5 years to 53 years with a mean of $22.75 \pm 15.59$ years. Total 30 (75\%) male and $10(25 \%)$ female patients are included in the study. The underlying etiology was found to be posttraumatic (67.5\%) 27 cases, followed by post-operative in 7 (17.5\%) and spontaneous in $6(15.0 \%)$ cases. Successful repair was observed in $36(90.0 \%)$. No significant difference was found in the frequency of successful repair among various age groups; 5-20, 21-36 and 37-53 years $(95.7 \%, 83.3 \%$ and $81.8 \% ; p=0.381)$, gender groups; male verses female $(86.2 \%$ and $100.0 \% ; p=0.194)$ and etiological groups; post-traumatic vs. postoperative vs. spontaneous (92.6\% vs. $71.4 \%$ vs. $100.0 \% ; p=0.169$ ).

Conclusions: The frequency of successful repair was found to be $90 \%$ in patients of CSF rhinorrhea treated through Endonasal endoscopic approach. No statistically significant difference was found in successful repair frequency across patient's gender, age and underlying cause of CSF rhinorrhea.
\end{abstract}

Keywords: CSF Rhinorrhea, Endonasal Endoscopic Approach, Successful Repair.

\section{INTRODUCTION}

Cerebrospinal fluid (CSF) rhinorrhea defines a breach of all barriers that separate the subarachnoid space from nasal cavity or paranasal sinus, skull base, Dura and arachnoid membrane. CSF rhinorrhea carries a significant mortality (as high as 10\%) and morbidity from ascending meningitis, pneumocephalus and brain abscess. Currently, there are two major operative approaches for the surgical management of CSF rhinorrhea, viz., trans-cranial sub-frontal approach and trans-nasal Endoscopic approach. The Endoscopic Endonasal approach has been advocated as the preferred approach in published literature as it gives proper exposure to the anterior skull base and sphenoid sinus and is associated with a higher success rate $(90-100 \%)$ and lower morbidity. However, no such local published material could be found.

Almost $80-85 \%$ of CSF rhinorrhea presented from accidental trauma, $16-18 \%$ is post-surgical and $4 \%$ are spontaneous. Post traumatic rhinorrhea, more than $50 \%$ presented within the first 2 days and $70 \%$ within 7 days and delayed cases present within the 3 months post injury. ${ }^{1,2}$ Males presented commonly with post traumatic rhinorrhea. The common site of CSF rhinorrhea after accidental trauma are the sphenoid sinus (30\%), frontal sinus (30\%), and ethmoid/ cribriform (23\%). ${ }^{4} \mathrm{CSF}$ rhinorrhea carries a significant mortality (as high as 10\%) and morbidity from ascending meningitis, pneumocephalus and brain abscess when inadequately treated..$^{5}$ 
Meningitis may occur in less than 20\% (8.8-41\%) of patients. This proportion increase with duration of CSF leak. ${ }^{6}$ There are two major treatment options conservative and surgical. Post traumatic CSF rhinorrhea spontaneously resolves in almost $90-95 \%$ with conservative management within 1-2 weeks, which includes head elevation, serial lumbar punctures or continuous lumbar drain. ${ }^{7}$ When conservative treatment fails, surgical treatment is indicated. Postsurgical and spontaneous rhinorrhea needs surgical treatment without conservative trial. Currently, there are two major operative approaches for the surgical management of CSF rhinorrhea, viz, trans-cranial subfrontal approach and trans-nasal endoscopic approach. In this era of minimally invasive surgery, endoscopic repair is increasingly being promoted when indicated as it avoids morbidities and complications associated with a transcranial approach like loss of olfaction, intracranial hemorrhage, brain edema, seizures, behavioral and personality changes. Tran cranial approach is usually reserved for leaks difficult to visualize or asses endoscopically like far lateral, posterior and superiorly based leaks or in case of multiple defects. The success rate with a transcranial approach varies from 48 to $73 \%{ }^{8}$ with high recurrence rate $27 \%$. The Endoscopic Endonasal approach has revolutionized as a superior approach to repair anterior skull base defects causing CSF rhinorrhea due to its excellent exposure of anterior skull base and sphenoid sinus.

The Endonasal Endoscopic approach is superior due to high success rate (90-100\%), low morbidity, limited hospital stays, olfaction preservation than transcranial approach ${ }^{10}$ as evident by other studies such as, of Burns et al (1996) reported $83 \%^{11}$, Bhalodiya et al. (2007) reported $85 \%$ success rate, ${ }^{12}$ Mattox et al. (1990) reported $86 \%$ success rate, ${ }^{13}$ Rohit et al. (2009) reported $90 \%$ success rate ${ }^{14}$ and Singh et al. (2010) reported $90 \%$ success rate. ${ }^{15}$ In the last few years, the Endoscopic Endonasal technique is being widely adopted in neurosurgical practice in Pakistan as CSF rhinorrhea is a common complication after anterior skull base fracture following head injury and is a rare entity. Failure of conservative management for more than 2 weeks warrants surgical intervention.

CSF rhinorrhea repair is neurosurgical domain and first time started in Lahore General Hospital with promising and successful results. We are the pioneering institution to adopt an Endoscopic Endonasal technique in Pakistan for the repair of CSF rhinorrhea. In our hospital, we have developed a special protocol for identification of the defect and successful CSF rhinorrhea repair. There is no local study available for this rare entity. The results of this study are expected to follow the trends documented in similar international studies and will help us to review our endoscopic skills and continue repair surgery at domestic level in Pakistan. The outcome of this study will enable us to compare our results with international results.

\section{MATERIALS AND METHODS}

\section{Study Design}

Prospective study. The study was conducted at Neurosurgery department, Unit II, Punjab institute of neurosciences (PINS), Lahore from 01/01/2014 to $30 / 06 / 2018$. This study involved 40 patients aged between 3-80 years of both genders diagnosed of CSF rhinorrhea with presented with in 1 week after trauma and spontaneous and postoperative cases.

\section{Inclusion Criteria}

Age (3 - 80 years) and irrespective of gender, all patients who had CSF rhinorrhoea as per operational definition presenting with either post traumatic, spontaneous, postoperative and delayed post traumatic leaks diagnosed with in the last 1 week.

\section{Exclusion Criteria}

Defects which were far lateral and involving the superior or posterior wall of the frontal sinus assessed by CT FESS protocol and not accessible via endoscope. Multiple skull base defects on CT FESS. Defects larger than $1.5 \mathrm{~cm}$ (calculated by CT FESS protocol).

Successful Repair: It was defined in terms of successful Endonasal Endoscopic CSF rhinorrhea repair. All patients who had clinical evidence CSF rhinorrhea (as per operational definition) when assessed at 2 weeks after surgery were declared to have successful repair.

CSF Rhinorrhea: Discharge of CSF from nose (> 5 $\mathrm{ml}$ ) when there was fistula on CT FESS protocol (presence of defect between $0.5-1.5 \mathrm{~cm}$ ) between the dura and skull base due to traumatic or non-traumatic causes. 
Spontaneous CSF Leaks: CSF rhinorrhea of anterior skull base that resulted spontaneously due to congenital skull base defects, iatrogenic causes.

Post-Operative CSF Leaks: CSF rhinorrhea that resulted after (24 to 48 hours) Endonasal Trans' sphenoidal surgery and anterior skull base surgery.

Delayed Post Traumatic Leaks: CSF rhinorrhea that started after 2 weeks of head injury onset and before 6 months.

\section{Data Collection}

After approval, informed consent from 40 patients with CSF rhinorrhea coming to OPD of Neurosurgery unit II, PINS fulfilling the inclusion criteria was taken. Questionnaire containing bio-data, i.e. age, sex, type of rhinorrhea (traumatic/non traumatic), the response to conservative treatment for 2 weeks was attached. Outcome measure in term of successful CSF repair was used as research protocol and post-operative findings, type of graft material used, any complication occurred were recorded by researcher himself.

A uniform protocol of surgery (endoscopic CSF leak repair) was adopted. Endoscopic technique was as follows: Patient position will be spine with head

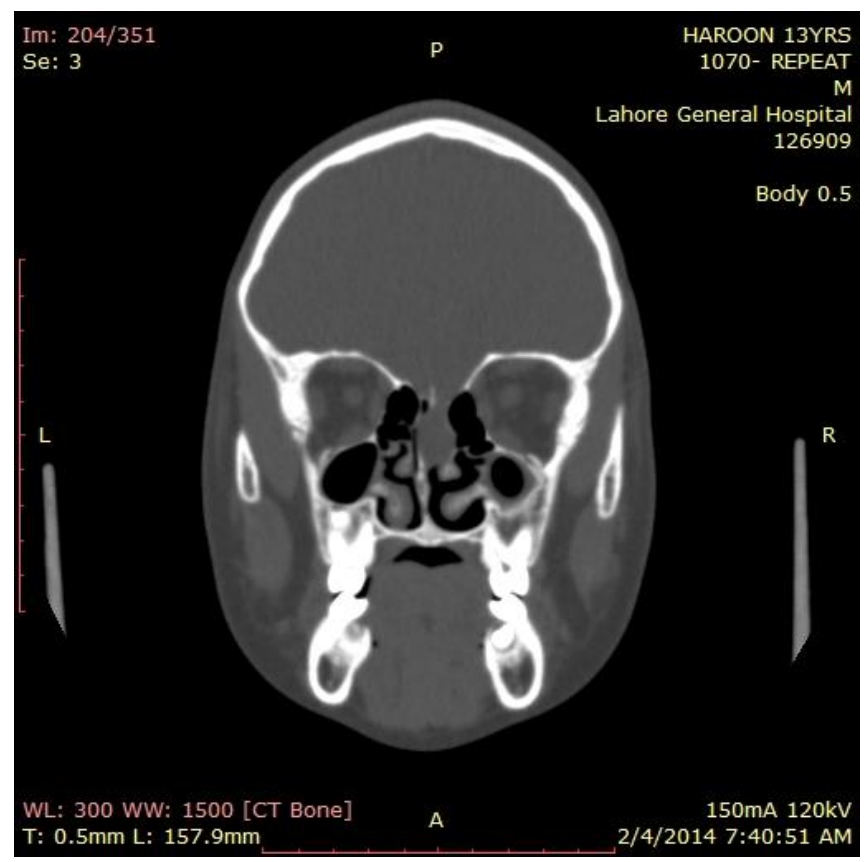

Fig. 1: CT FESS showing the defect on right side of cribriform plate with an associated protruding encephalocele. slightly extended and turned towards surgeon side. Nasal mucosa was infiltrated with $2 \%$ xynosine solution. Endoscope $4 \mathrm{~mm}$ advanced forwarded through right or left nostril, lateral or medial to middle turbinate as directed by CT FESS protocol Figure 1.

Middle turbinate was taken as an important landmark in CSF leak repair. HADAD FLAP raised in all cases. Endoscope advanced forwarded and the defect was identified with the help of fluorescein dye or by identifying associated encephalocele (Figure 2).
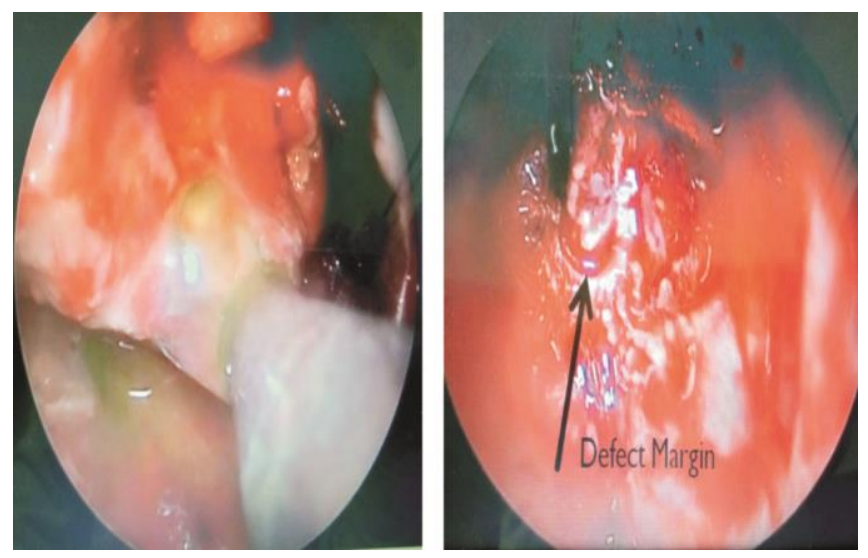

Fig. 2: Defect identified under endoscope with help of fluorescein.

Granulations tissue removed for clearing the defect and space created between Dura and anterior skull base for inlay or on lay graft placement i.e. fat, fascia lata and rotation of middle turbinate. The defect was further reinforced with the application of fibrin glue followed by nasal packing. CSF diversion procedures (lumber drain) used in few patients. All patients were treated according to department protocols under general anesthesia and patients were followed for 6 weeks to determine the success i.e. no clinical evidence of CSF rhinorrhea postoperatively and response was recorded as Yes (Successful repair)/No.

\section{Data Analysis}

All collected data analyzed via SPSS version 19. Numerical variables like age were presented by mean \pm SD. Categorical variables like sex, successful repair were presented as frequency and percentage. Data was stratified for age, gender, cause of CSF rhinorrhea to address effect modifiers. Post-stratification chi-square test has been applied taking the p-value $\leq 0.05$ as significant. 


\section{RESULTS}

\section{Age Incidence}

The patient's age ranged from 5 years to 53 years with a mean of $22.75 \pm 15.59$ years.

\section{Gender Distribution}

Out of 40 patients30 (75\%) were male and $10(25 \%)$ were female.

Table 1: Frequency Table for Underlying Cause of CSF Rhinorrhea $(n=40)$.

\begin{tabular}{|l|c|c|}
\hline $\begin{array}{l}\text { Underlying Cause of CSF } \\
\text { Rhinorrhea }\end{array}$ & Frequency & Percent \\
\hline $\begin{array}{l}\text { Post Traumatic CSF } \\
\text { Rhinorrhea }\end{array}$ & 27 & 67.5 \\
\hline $\begin{array}{l}\text { Post-Operative CSF } \\
\text { Rhinorrhea }\end{array}$ & 7 & 17.5 \\
\hline Spontaneous CSF Rhinorrhea & 6 & 15.0 \\
\hline Total & 40 & 100.0 \\
\hline
\end{tabular}

Table 2: Frequency Table for Successful Repair $(n=40)$.

\begin{tabular}{|l|c|c|}
\hline Successful Repair & Frequency & Percent \\
\hline Yes & 36 & 90.0 \\
\hline No & 4 & 10.0 \\
\hline Total & 40 & 100.0 \\
\hline
\end{tabular}

Table 3: Frequency Table for Successful Repair across Age Groups $(n=40)$.

\begin{tabular}{|c|c|c|c|c|}
\hline \multirow{2}{*}{ Age Groups } & \multicolumn{2}{|c|}{ Successful Repair } & \multirow{2}{*}{ Total } & \multirow{2}{*}{$\begin{array}{c}\mathbf{p} \\
\text { value }\end{array}$} \\
\hline & Yes & No & & \\
\hline \multirow{2}{*}{$\begin{array}{l}5-20 \text { years } \\
(\mathrm{n}=23)\end{array}$} & 22 & 1 & 23 & \multirow{6}{*}{$0.381 *$} \\
\hline & $95.7 \%$ & $4.3 \%$ & $100.0 \%$ & \\
\hline \multirow{2}{*}{$\begin{array}{l}21-36 \text { years } \\
(\mathrm{n}=6)\end{array}$} & 5 & 1 & 6 & \\
\hline & $83.3 \%$ & $16.7 \%$ & $100.0 \%$ & \\
\hline \multirow{2}{*}{$\begin{array}{l}37-53 \text { years } \\
(\mathrm{n}=11)\end{array}$} & 9 & 2 & 11 & \\
\hline & $81.8 \%$ & $18.2 \%$ & $100.0 \%$ & \\
\hline \multirow{2}{*}{ Total } & 36 & 4 & 40 & \\
\hline & $90.0 \%$ & $10.0 \%$ & $100.0 \%$ & \\
\hline
\end{tabular}

\section{Clinical Presentation and Management}

Underlying cause was post-traumatic in $27(67.5 \%)$ cases, followed by post-operative in $7(17.5 \%)$ and spontaneous in $6(15.0 \%)$ cases.

Table 4: Frequency Table for Successful Repair across Gender Groups $(n=40)$.

\begin{tabular}{|c|c|c|c|c|}
\hline \multirow{2}{*}{ Gender } & \multicolumn{2}{|c|}{ Successful Repair } & \multirow{2}{*}{ Total } & \multirow{2}{*}{$\begin{array}{c}\mathbf{p} \\
\text { value }\end{array}$} \\
\hline & Yes & No & & \\
\hline \multirow{2}{*}{$\begin{array}{l}\text { Male } \\
(\mathrm{n}=29)\end{array}$} & 25 & 4 & 29 & \multirow{5}{*}{$0.194 *$} \\
\hline & $86.2 \%$ & $13.8 \%$ & $100.0 \%$ & \\
\hline \multirow{2}{*}{$\begin{array}{l}\text { Female } \\
(\mathrm{n}=11)\end{array}$} & 11 & 0 & 11 & \\
\hline & $100.0 \%$ & $.0 \%$ & $100.0 \%$ & \\
\hline \multirow{2}{*}{ Total } & 36 & 4 & 40 & \\
\hline & $90.0 \%$ & $10.0 \%$ & $100.0 \%$ & \\
\hline
\end{tabular}

Chi-square test,

*Observed difference was statistically insignificant.

Successful repair was observed in 36 (90.0\%) patients. No statically significant difference was found in the frequency of successful repair across various age groups; 5-20, 21-36, 37-53 years $(95.7 \%, 83.3 \%$, $81.8 \% ; \mathrm{p}=0.381)$, gender groups; male vs. female ( $86.2 \%$ vs. $100.0 \% ; p=0.194)$ and etiological groups; post-traumatic vs. post-operative vs. spontaneous (92.6\% vs. $71.4 \%$ vs. $100.0 \% ; p=0.169)$.

\section{DISCUSSION}

Cerebrospinal fluid (CSF) rhinorrhea involves a breach of barriers of all barriers that separate the subarachnoid space from the nasal cavity or paranasal sinus, skull base, dura mater, and arachnoids membrane. Approximately $80 \%$ of CSF rhinorrhea result from accidental trauma, $16 \%$ from surgical procedures and $4 \%$ are spontaneous. Post traumatic rhinorrhea mostly present in 2 weeks. ${ }^{1,2}$ CSF rhinorrhea carries a significant mortality (as high as $10 \%$ ) and morbidity from ascending meningitis, pneumocephalus and brain abscess when inadequately treated. ${ }^{5}$ Meningitis may occur in less than $20 \%$ (8.8$41 \%$ ) of patients. This proportion may even increase to $58 \%$ with the duration of the leak. ${ }^{6}$

There are two major treatment options conservative and surgical. Previously transcranial approach was preferred for CSF rhinorrhea 
repair, but this was a cumbersome procedure, craniotomy and craniotomy scar and associated complications after a massive brain retraction to expose the skull base like anosmia, seizures, intracranial bleed, high risk of meningitis, injury to adjacent neurovascular structures ${ }^{17}$ and even death in some cases. Transcranial approach failure rate was up to $30 \%$ to $40 \% .^{18,19}$

The Endoscopic Endonasal approach has been advocated as the preferred approach in published literature as it gives exposure to anterior skull base and the sphenoid sinus and is associated with a higher success rate and lower morbidity.

The study objective was to evaluate the CSF rhinorrhea outcome repair with the Endonasal Endoscopic approach in terms of success of the repair. This study involved 40 patients aged between 3-80 years of both genders diagnosed of CSF rhinorrhea with in the last 1 week. Patient's age ranged from 5 years to 53 years with a mean of $22.75 \pm 15.59$ years. $29(72.5 \%)$ male and 11 $(27.5 \%)$ female patients are included in the study group. A relatively higher mean age of $36.3 \pm 11$ years was observed previously in patients of CSF rhinorrhea by Farooq et al. (2011) at Dow University of Health Sciences, Karachi. Similar to the present study, they also reported a similar male predominance $(56.5 \%$ vs. $43.5 \%)$ among such patients. $^{22}$ However, a female predominance (38\% vs. 62\%) was observed by Bhatti et al. in another local study at Ayyub Medical College, Abbottabad, and Pakistan 65.

The underlying cause was post-traumatic in $27(67.5 \%)$ cases, followed by post-operative in 7 $(17.5 \%)$ and spontaneous in $6(15.0 \%)$ cases. Our results matched with that of Sharma et al. (2010) who also observed similar etiology of cases of cases; posttraumatic $(\mathrm{n}=22,61.11 \%)$, post-operative $(\mathrm{n}=6$, $16.66 \%)$, and spontaneous $(\mathrm{n}=8,22.23 \%)^{15}$. Farooq et al. (2011) and Bhatti et al. (2011) also commented that traumatic CSF rhinorrhea being the most frequent observed in $74 \%$ and $76.19 \%$ cases respectively ${ }^{22,23}$.

The frequency of successful repair was found to be 90\% in patients of CSF rhinorrhea treated through
Table 6: Review of Existing Literature on Frequency of Successful Repair through Endonasal Endoscopic Approach.

\begin{tabular}{|l|l|l|c|}
\hline Study & Year & $\mathbf{n}$ & $\begin{array}{c}\text { Successful Repaired } \\
\text { in 1 } \\
\text { (t) } \\
\text { nttempt }\end{array}$ \\
\hline Sharma et al. ${ }^{15}$ & 2010 & 36 & $32(90.0 \%)$ \\
\hline Banks et al. $^{4}$ & 2009 & 193 & $176(91 \%)$ \\
\hline Presutti et al. $^{16}$ & 2009 & 52 & $46(88.5 \%)$ \\
\hline Rohit et al. $^{14}$ & 2009 & 11 & $10(91.0 \%)$ \\
\hline Lindstrom et al. $^{20}$ & 2004 & 36 & $32(89 \%)$ \\
\hline Briggs \& Wormald $^{21}$ & 2004 & 52 & $47(90 \%)$ \\
\hline Lee et al. & & & \\
\hline $\begin{array}{l}\text { Present Study } \\
\text { Ishfaq et al. }\end{array}$ & 2004 & 39 & $36(92 \%)$ \\
\hline
\end{tabular}

Endonasal Endoscopic approach. Our results are in line with a number of previously published studies; Sharma et al. (2010) reported $90.0 \%$ success, ${ }^{15}$ Briggs \& Wormald (2004) reported $90 \%$ success,${ }^{15,21}$ Rohit et al. (2009) reported $91.0 \%$ success, ${ }^{15,14}$ Banks et al. (2009) reported 91\% success, ${ }^{4}$ and Lee et al (2004) reported $92 \% .{ }^{21}$ No statistically significant difference was found in the frequency of successful repair among patient's age, gender and underlying cause of CSF rhinorrhea which shows that this procedure is equally effective for all age groups, genders and etiological 
types of CSF rhinorrhea making it an ideal choice.

The present study is unique in the local population and directs the use of the Endonasal Endoscopic approach for the treatment of patients with CSF rhinorrhea. Only limitation that should be considered in the present study and that is about complications. Complications should be considered before adopting this technique in routine practice. Such a study in future is highly recommended.

\section{CONCLUSION}

The frequency of successful repair was found to be $90 \%$ in patients of CSF rhinorrhea treated through Endonasal endoscopic approach. No statistically significant difference was found in the frequency of successful repair across patient's age, gender and underlying cause of CSF rhinorrhea.

\section{REFERENCES}

1. Hegazy HM, Carrau RL, Snyderman CH, Kassam A, Zweig J. Transnasal endoscopic repair of cerebrospinal fluid rhinorrhea: a meta-analysis. Laryngoscope, 2000; 110 (7): 1166-72.

2. Loew F, Pertuiset B, Chaumier EE, Jaksche $H$. Traumatic, spontaneous and postoperative CSF rhinorrhea. Adv Tech Stand Neurosurg. 1984; 11: 169207.

3. Friedman JA, Ebersold MJ, Quast LM. Post-traumatic cerebrospinal fluid leakage. World J Surg. 2001; 25: 1062-6.

4. Banks CA, Palmer JN, Chiu AG, O'Malley BW Jr, Woodworth BA, Kennedy DW, et al. Endoscopic closure of CSF rhinorrhea: 193 cases over 21 years. Otolaryngol Head Neck Surg. 2009; 140: 826-33.

5. Yilmazlar S, Arslan E, Kocaeli H, Dogan S, Aksoy K, Korfali E, et al. Cerebrospinal fluid leakage complicating skull base fractures: analysis of 81 cases. Neurosurg Rev. 2006; 29 (1): 64-71.

6. Asano T, Ohno K, Takada Y, Suzuki R, Hirakawa K, Monma S, et al. Fractures of the floor of the anterior cranial fossa. J Trauma. 1995; 39: 702-6.

7. Bell RB, Dierks EJ, Homer L, Potter BE. Management of cerebrospinal fluid leak associated with Craniomaxillofacial trauma. J Oral Maxillofac Surg. 2004; 62 (6): 676-84.

8. Marshall AH, Jones NS, Robertson IJ. CSF rhinorrhea: The place of endoscopic sinus surgery. Br J Neurosurg. 2001; 15: 8-12.

9. Ray BS, Bergland RM. Cerebrospinal fluid fistula: clinical aspects, techniques of localization and methods of closure. J Neurosurg. 2007; 30: 399-405.
10. Kumar BR, Sahu R, Srivastava AK, Nair AP, Mehrotra A. Surgically repaired posttraumatic CSF rhinorrhea: An institutional experience and review of literature. Indian J Neurosurg. 2012; 1: 23-7.

11. Burns JA, Dodson EE, Gross CW. Transnasal endoscopic repair of cranionasal fistulae: a refined technique with long term follow-up. Laryngoscope, 1996; 106: 1080-3.

12. Neena H, Bhalodiya P, Shawn TJ. Cerebrospinal fluid Rhinorrhea: Endoscopic repair based on a combined diagnostic approach. Indian J Otolaryngol Head Neck Surg. 2009; 61: 120-6.

13. Mattox DE. Kennedy DW. Endoscopic management of cerebrospinal fluid leaks and encephalocele. Laryngoscope, 1990; 100: 857-62.

14. Rohiy S, Produl H, Nayak DR, Balakrishanan R, Hazarika M, Ansulsingh K, et al. Endoscopic repair of cerebrospinal fluid Rhinorrhea-manipal Experience. Ind J Otolaryngol Head Neck Surg. 2009; 61 (1): 14-8.

15. Sharma DP, Singh D, Sinha S, Srivastva AK, Singh H, Jagetia A. CSF rhinorrhea: An overview of endoscopic repair. J Ind Neurotr. 2010; 2 (7): 157-62.

16. Dodson EE, Gross CW, Swerdloff JL, Gustafson LM. Trans nasal endoscopic repair of cerebrospinal fluid rhinorrhea and skull base defect: a review of twentynine cases. Otolaryngology Head Neck Surg. 2014; 111: 600-5.

17. Hirsch O. Successful closure of cerebrospinal fluid rhinorrhoea by Endonasal surgery. Arch Otolaryngol. 1952; 56: 1-13.

18. Park JI, Strelzow VV, Friedman WH. Current management of cerebrospinal fluid rhinorrhoea. Laryngoscope, 1983; 93: 1294-1300.

19. Hubbard JL, McDonald TJ, Pearson BW, Laws ER. Spontaneous cerebrospinal fluid rhinorrhoea: evolving concepts in diagnosis and surgical management based on the Mayo Clinic experience from 1970 through 1981. Neurosurgery, 1985; 16: 314-21.

20. Lindstrom D R, Toohill R J, Loehrl T A, Smith T L. Management of cerebrospinal fluid rhinorrhea: The Medical College of Wisconsin experience. Laryngoscope, 2004; 114: 969-74.

21. Kirtane MV, Gautham K, Upadhyaya SR. Endoscopic CSF rhinorrhea closure: our experience in 267 cases. Otolaryngol Head Neck Surg. 2005; 132 (2): 208-12.

22. Farooq MU, Ansari MA. Cerebrospinal fluid rhinorrhea: etiology, site of leakage and endoscopic management. J Coll Physicians Surg Pak. 2011; 21 (8): 460-3.

23. Bhatti SN, Khan SA, Shah R, Aurangzeb A, Ahmed E, Rizvi F, et al. Trans nasal endoscopic repair of cerebrospinal fluid rhinorrhea. J Ayyub Med College Abbott. 2011; 23 (2): 15-7. 


\section{Additional Information}

Disclosures: Authors report no conflict of interest.

Ethical Review Board Approval: The study was conformed to the ethical review board requirements.

Human Subjects: Consent was obtained by all patients/participants in this study.

Conflicts of Interest:

In compliance with the ICMJE uniform disclosure form, all authors declare the following:

Financial Relationships: All authors have declared that they have no financial relationships at present or within the previous three years with any organizations that might have an interest in the submitted work.

Other Relationships: All authors have declared that there are no other relationships or activities that could appear to have influenced the submitted work.

Address for Correspondence:

Dr. Muhammad Ishfaq

Punjab Institute of Neurosciences, Lahore - Pakistan

Email: ishfaq141_dr@yahoo.com

\section{AUTHORSHIP AND CONTRIBUTION DECLARATION}

\begin{tabular}{|c|c|c|c|}
\hline Sr.\# & Author's Full Name & Intellectual/Contribution to Paper in Terms of: & \\
\hline 1. & $\begin{array}{l}\text { Muhammad Ishfaq } \\
\text { (Main/Principal Author). }\end{array}$ & 1. Proposed topics and Basic Study Design. & \\
\hline 2. & $\begin{array}{l}\text { Talha Abbas } \\
\text { (2nd Author) }\end{array}$ & 2. Data collection and calculations & \\
\hline 3. & $\begin{array}{l}\text { Muhammad Akmal } \\
\text { (3rd Author) }\end{array}$ & 3. Analysis of data. & Signature by the \\
\hline 4. & $\begin{array}{l}\text { Nabeel Choudhry } \\
\text { (4th Author) }\end{array}$ & 4. Manuscript writing & (x)ey \\
\hline 5. & $\begin{array}{l}\text { Adeeb-ul-Hassan } \\
\text { (5th Author) }\end{array}$ & $\begin{array}{l}\text { 5. Paper writing, referencing, Data Calculations and } \\
\text { quality insurer }\end{array}$ & \\
\hline 6. & $\begin{array}{l}\text { Omair Afzal } \\
\text { (6th Author) }\end{array}$ & 6. Study Design and methodology & \\
\hline 7. & $\begin{array}{l}\text { Imran Siddiqui } \\
\text { 76th Author) }\end{array}$ & 7. Interpretation of results & \\
\hline 8. & $\begin{array}{l}\text { Khalid Mahmood } \\
\text { (8th Author) }\end{array}$ & 8. Literature review & \\
\hline
\end{tabular}

Date of Submission: 23-10-2019

Date of Revision: 10-12-2019

Date of Online Publishing: 25-12-2019

Date of Print: 31-12-2019 